\title{
Inseticidas botânicos aplicados sobre Aphis gossypii e seu predador Cycloneda sanguinea em algodão-colorido
}

\author{
Mariana Oliveira Breda(1), José Vargas de Oliveira(1), Edmilson Jacinto Marques( ${ }^{(1)}$, \\ Rachel Gonçalves Ferreira( ${ }^{(2)}$ e Mauricéa Fidelis Santana ${ }^{(1)}$
}

\begin{abstract}
(1)Universidade Federal Rural de Pernambuco, Departamento de Agronomia, Rua Dom Manoel de Medeiros, s/no, Dois Irmãos, CEP 52171-900 Recife, PE. E-mail: breda.mariana@hotmail.com, vargasoliveira@uol.com.br, emar@depa.ufrpe.br, agrocea@yahoo.com.br (2)Pernambuco Participações e Investimentos S/A, Secretaria de Administração de Pernambuco, Rua Dr. João Lacerda, oㅜ 395, Cordeiro, CEP $50711-902$ Recife, PE. E-mail: rachelgferreira@yahoo.com.br
\end{abstract}

Resumo - O objetivo deste trabalho foi avaliar os efeitos de inseticidas botânicos sobre Aphis gossypii e seu predador Cycloneda sanguinea, em algodão-colorido. Foram avaliados inseticidas botânicos à base de azadiractina, extrato aquoso de sementes de nim e óleo de mamona, nas concentrações de 0 a $2 \%$, de 0 a $2,5 \%$ e de 0 a $3 \%$, respectivamente. Os bioensaios, em delineamento inteiramente casualizado, foram realizados em laboratório. A mortalidade do pulgão variou de 64 a 100\% para azadiractina; 12 a 92\% para extrato aquoso de nim; e 8 a $68 \%$ para óleo de mamona. A taxa instantânea de crescimento mostrou-se negativa a partir da concentração 1,25\% para azadiractina, 2,25\% para extrato aquoso de nim, e 3,0\% para óleo de mamona. Todos os inseticidas apresentaram toxicidade para larvas de 1o instar do predador, com mortalidade de 96,7 a $100 \%$ para azadiractina e extrato aquoso de nim, e de 50 a 100\% para óleo de mamona. Para o 4 io instar, a mortalidade variou de 87,5 a $100 \%$ para azadiractina, 73,3 a $100 \%$ para o extrato de nim, e 43,3 a 100\% para o óleo de mamona. Os inseticidas testados são promissores para o manejo de $A$. gossypii, porém mostraram-se pouco seletivos a $C$. sanguinea.

Termos para indexação: Azadirachta indica, azadiractina, crescimento populacional, extrato aquoso de nim, inseticidas naturais, óleo de mamona.

\section{Botanical insecticides applied on Aphis gossypii and its predator Cycloneda sanguinea on naturally colored cotton}

\begin{abstract}
The objective of this work was to evaluate the effects of botanical insecticides on Aphis gossypii and its predator Cycloneda sanguinea, in naturally colored cotton. The botanical insecticides based on azadirachtin, aqueous extract of nim seeds, and castor oil were tested at the concentrations from 0 to $2 \%, 0$ to $2.5 \%$, and 0 to $3 \%$, respectively. The bioassays were performed in laboratory conditions, in a completely randomized design. Aphid mortality ranged from: 64 to $100 \%$ for azadirachtin; 12 to $92 \%$ for nim aqueous extract; and 8 to $68 \%$ for castor oil. The instantaneous rate of increase reached negative values starting from concentrations of: $1.25 \%$, for azadirachtin; $2.25 \%$, for nim aqueous extract; and 3.0\%, for castor oil emulsion. All insecticides were toxic to the first instar larvae of the predator, with mortality values from 96.7 to $100 \%$, for azadirachtin and nim aqueous extract, and from 50 to $100 \%$ for castor oil emulsion. For the $4^{\text {th }}$ instar larvae, mortalities ranged from 87.5 to $100 \%$ for azadirachtin; from 73.3 to $100 \%$ for nim aqueous extract; and from 43.3 to $100 \%$ for castor oil emulsion. The tested insecticides are promising for A. gossypii management, although they are not selective toward $C$. sanguinea.
\end{abstract}

Index terms: Azadirachta indica, azadirachtin, population growth, nim aqueous extract, natural insecticides, castor oil emulsion.

\section{Introdução}

O algodão-colorido (Gossypium hirsutum L.) desponta como uma das principais alternativas para a cotonicultura no Semiárido Nordestino (Carvalho, 2006). A coloração natural das fibras dispensa o tingimento artificial e valoriza os novos produtos que, quando cultivados em sistemas orgânicos ou agroecológicos agregam-lhe ainda mais valor comercial (Souza, 2000). Entre as cultivares de algodão-colorido, destaca-se a BRS Verde, que apresenta capulhos naturalmente esverdeados e é adaptada às especificidades da agricultura familiar no Nordeste do Brasil (Wanderley Junior et al., 2002).

Um dos grandes entraves para a consolidação sustentada do cultivo de algodão, nessa região, é o ataque de pragas (Santos, 1999), com destaque para o pulgão Aphis gossypii Glover, bastante comum e prejudicial, que causa danos diretos e indiretos à produção (Santos et al., 2004; Gabriel, 2010). Este

Pesq. agropec. bras., Brasília, v.46, n.11, p.1424-1431, nov. 2011 
inseto ocorre praticamente em todas as fases fenológicas das cultivares de algodão, desde a germinação até o fim do ciclo da cultura (Furtado et al., 2009).

As principais estratégias alternativas para o controle de A. gossypii, em sistemas familiares de produção orgânica ou agroecológica, são o controle biológico, com aproveitamento da presença de inimigos naturais no campo, e o uso de produtos naturais, principalmente os de origem vegetal, conforme Queiroga et al. (2008).

A utilização de inseticidas botânicos tem sido bastante difundida em programas de manejo de pragas, mas para que essa tecnologia seja eficiente há a constante necessidade de obtenção e avaliação de novos compostos bioativos (Ribeiro et al., 2009). Nos últimos anos, a azadiractina, derivada do nim (Azadirachta indica A. Juss.), vem sendo avaliada por seu potencial de inibir o crescimento, alimentação e desenvolvimento de insetos-praga (Mordue et al., 2010). Outro composto de comprovado efeito inseticida sobre diversas pragas é a ricina, proveniente de sementes de mamona (Ricinus communis L.), espécie adaptada às condições de cultivo no Semiárido Nordestino (Almeida et al., 2005; Santiago et al., 2008).

A joaninha, Cycloneda sanguinea L., é um dos inimigos naturais de maior impacto na regulação populacional de A. gossypii no Brasil (Cosme et al., 2007). Ela é bastante comum e alimenta-se das áfideos, durante as fases larval e adulta, em diferentes culturas (Soares \& Busoli, 2000; Santa-Cecília et al., 2001; Guerreiro et al., 2002).

Trabalhos que visam avaliar os efeitos de inseticidas botânicos no manejo de $A$. gossypii, e a possibilidade de associá-los ao predador C. sanguinea em programas de controle biológico, são ainda incipientes. Os efeitos de inseticidas botânicos sobre pragas e inimigos naturais vêm sendo analisados a partir das estimativas de toxicidade ou seletividade, baseadas em doses $\left(\mathrm{DL}_{50}\right)$ ou concentrações $\left(\mathrm{CL}_{50}\right)$ letais médias (Desneux et al., 2007).

Uma medida alternativa a esses métodos tem sido a estimativa da taxa instantânea de crescimento $\left(\mathrm{r}_{\mathrm{i}}\right)$ (Stark \& Banks, 2003), que permite avaliar os efeitos letais e subletais desses produtos sobre uma população, após um tempo previamente determinado, integrandose valores de sobrevivência e fecundidade.

O objetivo deste trabalho foi avaliar os efeitos letais e subletais dos inseticidas botânicos azadiractina, extrato aquoso de nim e óleo emulsionável de mamona sobre $A$. gossypii, por meio da taxa instantânea de crescimento (ri), e avaliar a toxicidade desses produtos sobre $C$. sanguinea.

\section{Material e Métodos}

A criação de $A$. gossypii foi estabelecida conforme Oliveira et al. (2010), em sala climatizada a $27 \pm 1^{\circ} \mathrm{C}$, $70 \pm 5 \%$ de umidade relativa (UR) e fotófase de 12 horas. Sementes da cultivar de algodoeiro BRS Verde foram semeadas em bandejas de isopor de $32 \mathrm{~cm}^{2}$ (64 células), com substrato Base Plant - constituído de casca de pinus, vermiculita, turfa, corretivos de acidez e aditivos -, e mantidas em casa de vegetação.

Dez dias após a semeadura do algodão, as bandejas foram transferidas para o laboratório e colocadas em gaiolas teladas com $1,0 \times 1,20 \times 0,6 \mathrm{~m}$. Para estimular a atividade fotossintética, as plantas foram mantidas sob lâmpadas fluorescentes que forneciam disponibilidade diária de 4.250 lux de intensidade luminosa, com fotófase de 12 horas. Inicialmente, as plantas foram infestadas com colônias de A. gossypii, obtidas em algodoeiro, no Campus da Universidade Federal Rural de Pernambuco, a cada 20 dias e, quando necessário, novas infestações foram realizadas.

Para a criação de $C$. sanguinea, foram utilizados potes de plástico de $10 \mathrm{~cm}$ de altura por $10 \mathrm{~cm}$ de diâmetro, mantidos a $25 \pm 1^{\circ} \mathrm{C}$ e $70 \pm 5 \%$ UR. Dentro dos recipientes, foram confinados até dois casais adultos de $C$. sanguinea. Diariamente, os casais recebiam folhas de algodoeiro com colônias de A. gossypii como alimento. Na tampa dos potes, foram feitos orifícios de $2 \mathrm{~cm}$ de diâmetro, cobertos com tecido do tipo "voile". As paredes internas foram revestidas com sulfite, para oviposição, e, no fundo do recipiente, espalhou-se uma lâmina de $2 \mathrm{~cm}$ de ágar-água a $1 \%$ para prolongar a turgidez das folhas de algodoeiro.

Os ovos depositados no papel-ofício foram retirados com o auxílio de uma tesoura ou pincel, e mantidos em placas de Petri de $12 \mathrm{~cm}$ de diâmetro, com papel de filtro umedecido, até a eclosão das larvas. Em seguida, as larvas foram transferidas individualmente para outras placas de Petri, com ágar-água a $1 \%$, e alimentadas com A. gossypii até a fase de pupa, por meio de técnica adaptada de Boiça Júnior et al. (2004).

Os inseticidas botânicos utilizados nos bioensaios foram: azadiractinas A e B (Azamax, DVA Especialidades, Comércio, Importação, Exportação 
de Insumos Agropecuários Ltda., São Paulo, SP, Brasil); óleo emulsionável de sementes de mamona (R. communis), proveniente da fazenda Tamanduá, Patos, PB; extrato aquoso de nim, obtido por meio da maceração de sementes provenientes da Usina Cruangi, Timbaúba, PE.

Para avaliar a mortalidade de A. gossypii e os efeitos sobre o crescimento populacional do afídeo, os inseticidas botânicos foram utilizados em concentrações determinadas em bioensaios preliminares. A azadiractina foi testada nas concentrações $0 ; 0,25 ; 0,50$; 0,$75 ; 1,0 ; 1,25 ; 1,50 ; 1,75$ e 2,0\%; o óleo emulsionável de sementes de mamona a $0 ; 0,25 ; 0,50 ; 0,75 ; 1,0$; 1,$25 ; 1,50 ; 1,75 ; 2,0 ; 2,25 ; 2,5 ; 2,75$ e $3,0 \%$; e o extrato aquoso de nim a $0 ; 0,25 ; 0,50 ; 0,75 ; 1,0 ; 1,25 ; 1,50$; 1,$75 ; 2,00 ; 2,25$ e $2,50 \%$.

Utilizou-se o delineamento experimental inteiramente ao acaso, com oito repetições por tratamento. Para isso, a cultivar de algodão-colorido BRS Verde foi semeada em vasos de $5 \mathrm{~L}$, com areia e húmus de minhoca à proporção de $2: 1$, e mantida em casa de vegetação até que as plantas atingissem cerca de 20 dias de idade. Após esse período, discos de folhas de $5 \mathrm{~cm}$ de diâmetro foram imersos nos diferentes tratamentos de calda inseticida e, para o tratamento testemunha, imersos em água destilada.

Após a imersão e a secagem dos discos por $30 \mathrm{~min}$, cinco fêmeas adultas e ápteras de $A$. gossypii foram transferidas para os discos tratados, em placas de Petri de plástico, seladas lateralmente com parafilme e acondicionadas em câmara climatizada a $25 \pm 1{ }^{\circ} \mathrm{C}$, $70 \pm 5 \%$ UR e fotófase de 12 horas. Para a avaliação do efeito letal, observou-se, diariamente, a mortalidade de adultos; para a avaliação dos efeitos subletais, foi realizada a contagem de adultos e ninfas presentes nos discos durante 10 dias. A partir desses dados, a taxa instantânea de crescimento $\left(r_{i}\right)$ foi calculada, de acordo com a equação $\mathrm{r}_{\mathrm{i}}=\ln \left(\mathrm{N}_{\mathrm{f}} / \mathrm{N}_{\mathrm{o}}\right) / \Delta \mathrm{t}$, em que: $\mathrm{N}_{\mathrm{f}}$ é o número de pulgões (ninfas e adultos) presentes em cada disco na avaliação final, aos 10 dias; $\mathrm{N}_{\mathrm{o}}$ é o número inicial de pulgões; e $\Delta$ t é o período de duração do bioensaio (Stark \& Banks, 2003).

Nos bioensaios de ação letal e subletal dos tratamentos sobre $C$. sanguinea, e com base nos bioensaios com A. gossypii, foram testadas as seguintes concentrações de cada inseticida: 0,25 e 1,5\%, para azadiractina; 1,25 e 3,0\%, para o óleo emulsionável de sementes de mamona; 1,0 e 2,25\%, para o extrato aquoso de nim. Para a testemunha, foi utilizada água destilada. Discos de folhas de 3,5 cm de diâmetro da cultivar BRS Verde, previamente infestada com colônias de A. gossypii, foram pulverizados com $0,5 \mathrm{~mL}$ das caldas inseticidas nas concentrações mencionadas, com o auxílio de um microatomizador Paasche Airbusch elétrico, acoplado a um compressor, calibrado a uma pressão de $9 \mathrm{~Pa}$ e, em seguida, foram secos à temperatura ambiente.

Depois de secos, os discos infestados com pulgões foram colocados individualmente em placa de Petri de plástico, com uma camada de ágar-água a $1 \%$, à qual foi adicionada uma larva de $1^{\circ}$ ou $4^{\circ}$ instar de C. sanguinea. Esses instares foram selecionados para observar diferenças de suscetibilidade entre estágios de desenvolvimento do predador. As placas foram seladas lateralmente com parafilme e acondicionadas em câmara climatizada a $25 \pm 1^{\circ} \mathrm{C}, 70 \pm 5 \%$ UR e fotófase de 12 horas. As avaliações foram realizadas diariamente, tendo-se acompanhado o desenvolvimento das larvas, a mortalidade, a viabilidade pupal e a emergência de adultos. Os experimentos foram realizados em delineamento inteiramente casualizado, com dez repetições.

Realizaram-se as análises de variância, e as médias foram comparadas pelo teste de Tukey, a 5\% de probabilidade, para os parâmetros dos bioensaios de toxicidade letal e subletal sobre A. gossypii. No caso de respostas significativas, os dados de mortalidade média de ninfas e de crescimento populacional foram submetidos à análise de regressão, tendo-se selecionado as equações que melhor representavam a resposta biológica, de acordo com sua significância ( $F$ e p) e coeficiente de determinação $\left(\mathrm{R}^{2}\right)$.

As análises foram realizadas por meio do programa SAS (SAS Institute, 2001), e as curvas de regressão pelo Programa SigmaPlot 10 (Systat Software, 2006). Para os experimentos de toxicidade sobre C. sanguinea, os dados foram submetidos à análise de variância, e as médias foram comparadas pelo teste de Tukey, a 5\% de probabilidade.

\section{Resultados e Discussão}

Os inseticidas botânicos, testados sobre fêmeas ápteras de $A$. gossypii, apresentaram diferentes padrões de mortalidade (Figura 1). Para azadiractina, a menor concentração $(0,25 \%)$ promoveu mortalidade de $64 \%$, tendo atingido $100 \%$ a partir da concentração de $1,5 \%$. No entanto, o número médio de ninfas de $A$. gossypii foi drasticamente reduzido a partir da concentração $0,25 \%$, 
e chegou a zero na concentração $2,0 \%$. No tratamento com extrato aquoso de nim, entretanto, houve variações significativas na mortalidade de $A$. gossypii, de acordo com a concentração utilizada: de $12 \%$, na menor concentração (0,25\%), a 92\% na concentração de 2,5\%. $\mathrm{O}$ número médio de ninfas, neste tratamento, também variou em consequência do aumento das concentrações, tendo chegado a 2,6 ninfas por disco de folha de algodão, na maior concentração $(2,5 \%)$.

A mortalidade provocada pelo óleo emulsionável de mamona variou de 8,0 a $68 \%$; porém, não houve diferença significativa entre as diversas concentrações avaliadas $(0$ a $3,0 \%)(p=0,102)$. Esse resultado indica um baixo efeito letal do produto sobre adultos de A. gossypii, mesmo em concentrações consideradas elevadas (acima de 2,0\%) e economicamente inviáveis para produtos de origem vegetal. Entretanto, o número médio de ninfas reduziu-se linearmente com o aumento das concentrações, tendo variado de 123,2 na testemunha a 2,4 na concentração de 3,0\% (Figura 2).

De maneira geral, os resultados acima estão de acordo com Santos et al. (2004) que, ao estudar a mortalidade de ninfas de $A$. gossypii, encontraram valores de 60 e $100 \%$ nas concentrações de $410(0,4 \%)$ e $1.410 \mathrm{mg}$ por $100 \mathrm{~mL}(1,4 \%)$ de extratos de nim, respectivamente. Breda et al. (2010), ao analisar a toxicidade letal de inseticidas botânicos sobre adultos ápteros desse pulgão, obtiveram valores de toxicidade letal baseados em $\mathrm{CL}_{50}$, que variaram de $10,15(1,015 \%)$ a $13,37 \mathrm{~mL} \mathrm{~L}^{-1}(1,337 \%)$, para produtos à base de nim. Esses autores também constataram valores de 22,58 $\left(2,258 \%, \mathrm{CL}_{50}\right)$ e de $142,36 \mathrm{~mL} \mathrm{~L}^{-1}\left(14,2 \%, \mathrm{CL}_{90}\right)$ para o óleo de pinhão-manso, planta pertencente à mesma família da mamona (Euphorbiaceae). Esses valores indicam, a exemplo dos observados neste trabalho, a baixa toxicidade desse produto.
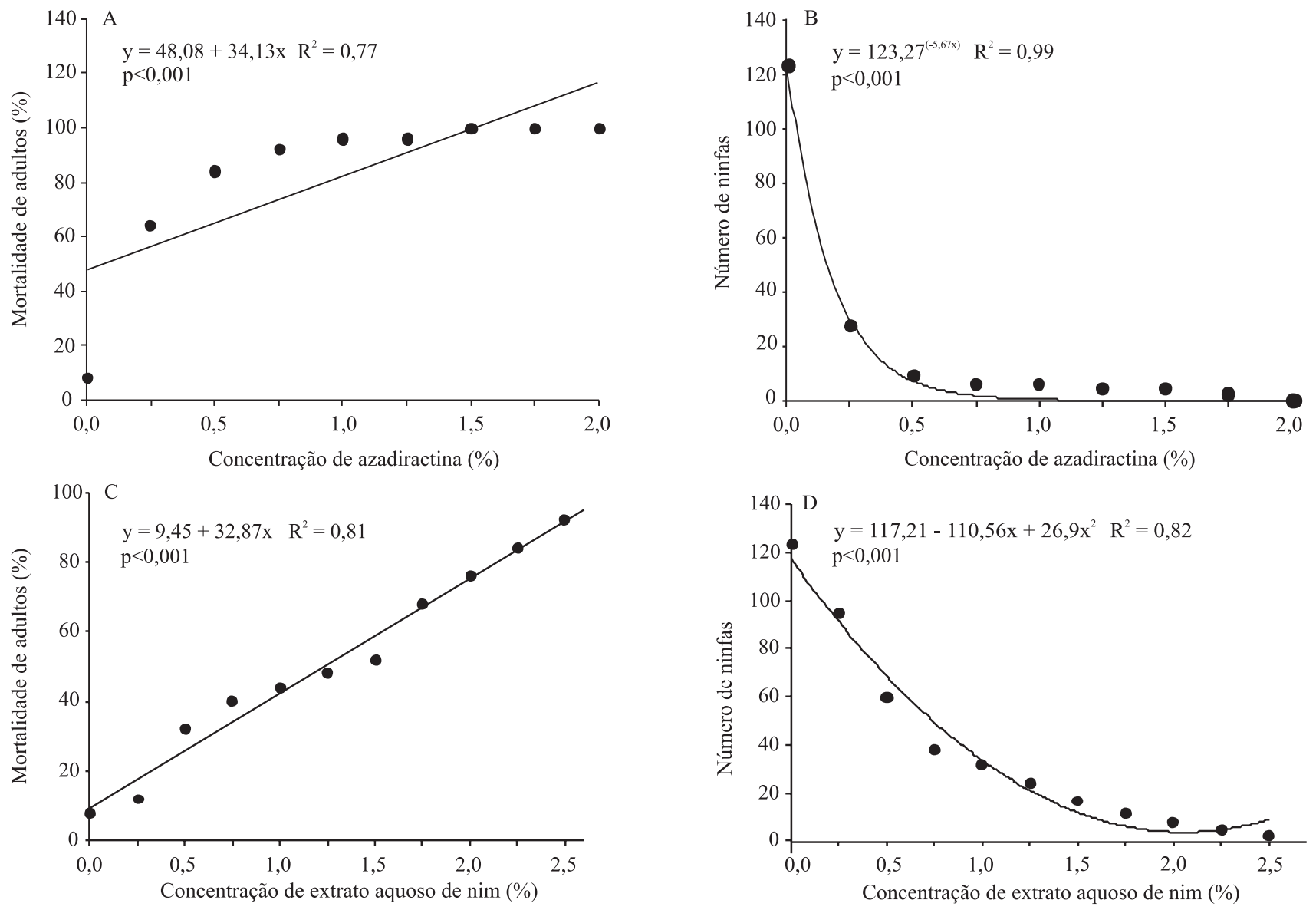

Figura 1. Percentagem média de mortalidade de fêmeas adultas ápteras e número médio de ninfas de Aphis gossypii, em discos de folha de algodão colorido 'BRS Verde' submetidos a diferentes concentrações de azadiractina (A e B) e de extrato aquoso de nim (C e D). Avaliações realizadas aos 10 dias de experimento. 
Em relação à ação subletal dos inseticidas sobre A. gossypii, todos causaram redução significativa no crescimento populacional do pulgão em consequência do aumento das concentrações. Não foi possível calcular a taxa instantânea de crescimento $\left(\mathrm{r}_{\mathrm{i}}\right)$ para a concentração de azadiractina a $2,0 \%$, em razão da mortalidade de $100 \%$ de adultos e ninfas.

Apesar de a azadiractina ter causado mortalidade de $100 \%$ em adultos, nas concentrações de 1,5, 1,75 e 2,0\% (Figura 1), a presença de ninfas vivas, após 10 dias de tratamento, possibilitou o cálculo da taxa instantânea que, a partir da concentração de 1,25\%, mostrouse negativa, o que indica declínio no crescimento populacional de $A$. gossypii, com tendência de supressão total das colônias (Figura 3 A). Por sua vez, o extrato aquoso de nim obteve $r_{i}$ negativas, a partir da concentração $2,25 \%$. O óleo de mamona, apesar da baixa ação letal, reduziu o crescimento populacional de $A$. gossypii em todas as concentrações testadas, e só apresentou valores negativos para a taxa instantânea de crescimento a $3,0 \%$.

Os resultados obtidos indicam que a azadiractina foi o inseticida de maior efeito letal e subletal sobre A. gossypii, pois, nas menores concentrações, ocasionou maior percentagem de mortalidade de adultos e $r_{i}$ negativas (Figura 3 ). No entanto, o extrato aquoso de nim e o óleo de mamona também apresentam potencial de utilização no manejo desse pulgão, mesmo a concentrações que apresentam $r_{i}$ positivas. Para tanto, deveriam ser adotadas amostragens periódicas e, possivelmente, aplicações adicionais,

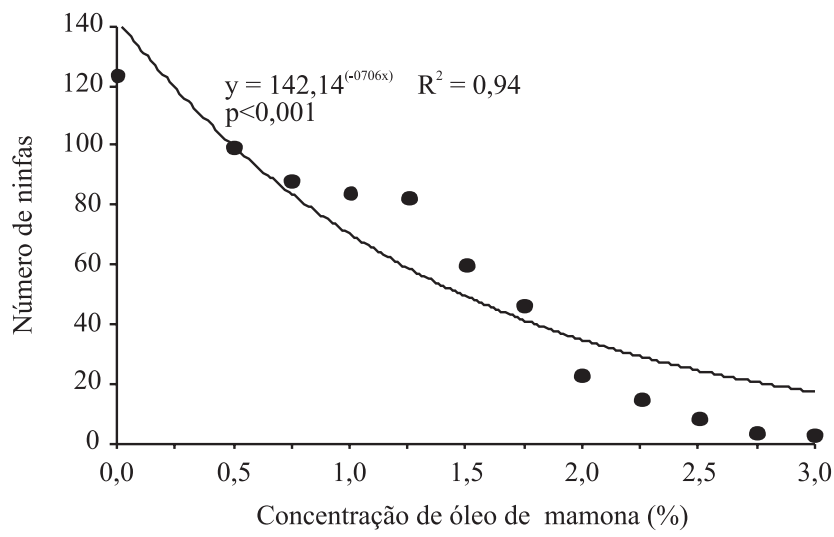

Figura 2. Número médio de ninfas de Aphis gossypii, em discos de folha de algodão colorido 'BRS Verde' submetidos a diferentes concentrações de óleo de mamona, a $25 \pm 1^{\circ} \mathrm{C}$, $70 \pm 5 \%$ de UR e fotófase de 12 horas. Avaliações realizadas aos 10 dias de experimento. para reduzir a população a níveis que não causem danos econômicos.

Andrade (2010) analisou o crescimento populacional de $A$. gossypii submetido a diferentes inseticidas botânicos, e observou $\mathrm{r}_{\mathrm{i}}$ negativas para os produtos Compostonat e Neempro, ambos à base de nim, a partir da concentração
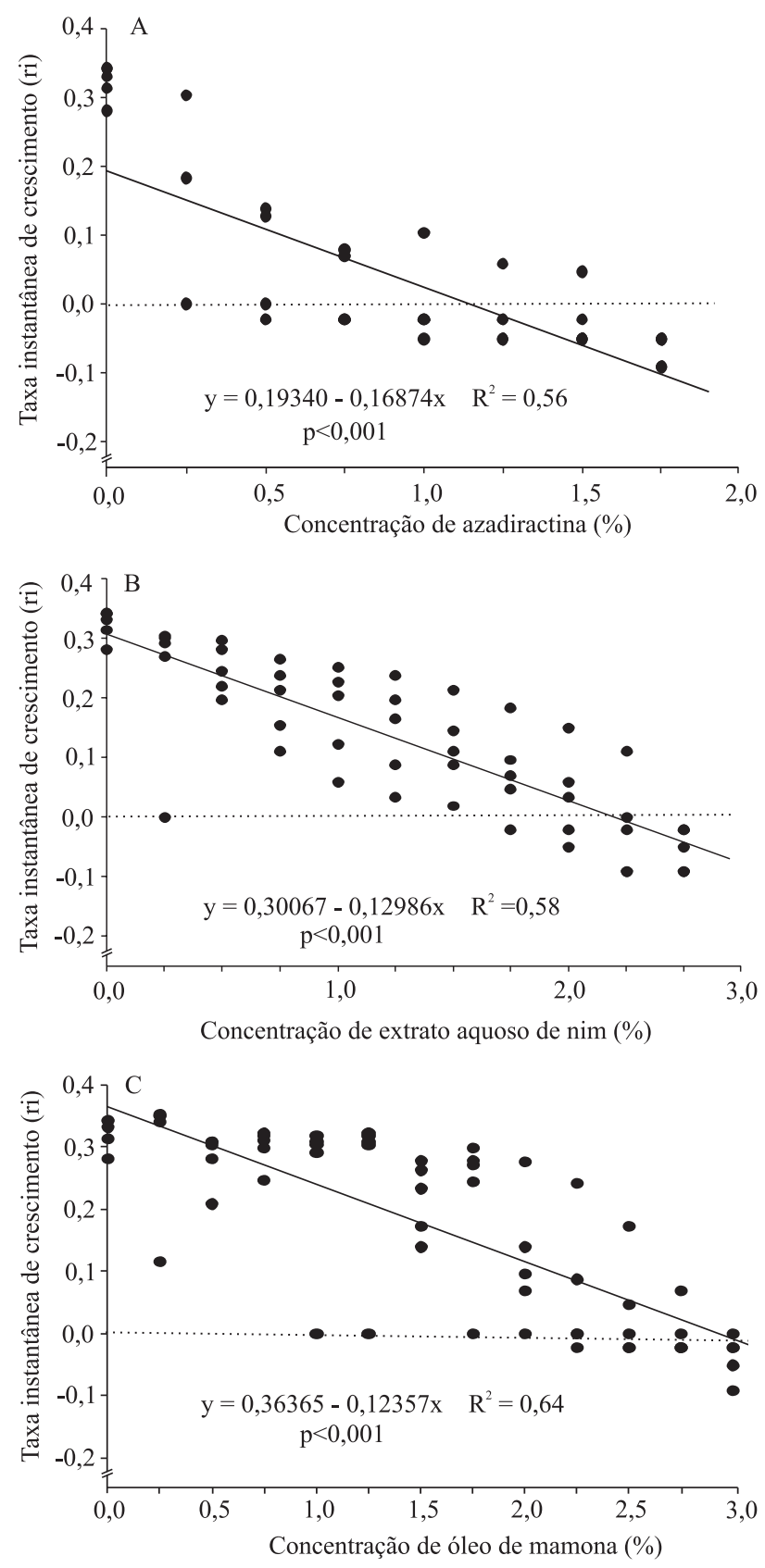

Figura 3. Taxa instantânea de crescimento $\left(\mathrm{r}_{\mathrm{i}}\right)$ observada $(\bullet)$ e estimada (reta), para fêmeas adultas ápteras de A. gossypii, em discos de folhas de algodão colorido 'BRS Verde' tratados com azadiractina (A), extrato aquoso de nim (B) e óleo de mamona (C). 
de $1,5 \%$. No entanto, Souza (2010), ao estudar os efeitos letal e subletal de óleo de nim sobre $A$. gossypii, obteve $\mathrm{r}_{\mathrm{i}}$ negativa apenas na maior concentração utilizada $\left(0,0148 \mu \mathrm{g} \mathrm{mL}^{-1}\right.$ dei.a. $)$ da formulação comercial DalNeem. Venzon et al. (2007), ao avaliar o efeito do extrato de nim (NeemAzal T/S) sobre Myzus persicae (Sulzer) e Eriopis connexa (Germar), em folhas de pimenteira, verificaram que, nas concentrações 0,5 e 1,0\%, houve significativa redução do crescimento populacional do pulgão, ainda que com $r_{i}$ positivas.

Apesar do potencial para utilização no manejo de A. gossypii, a azadiractina, o extrato aquoso de nim e o óleo de mamona mostraram toxicidade significativa a larvas de $1^{\circ}$ e $4^{\circ}$ instares de $C$. sanguinea, tanto em concentrações letais quanto subletais para o pulgão (Tabela 1). A azadiractina a $0,25 \%$ ocasionou 96,7 e $87,5 \%$ de mortalidade a larvas de $1^{\circ}$ e $4^{\circ}$ instares, respectivamente. A concentração de $1,5 \%$ provocou mortalidade de $100 \%$ para ambos os instares, assim como a de $2,25 \%$ do extrato aquoso de nim. Em todos os tratamentos mencionados, a emergência de adultos foi nula e, em alguns casos, houve adultos malformados (metamorfose incompleta), os quais

Tabela 1. Percentagem de mortalidade larval, viabilidade pupal e emergência de adultos, a partir de larvas de $1^{\circ}$ e $4^{\circ}$ instares de Cycloneda sanguinea, em discos de folhas de algodão colorido 'BRS Verde', infestados com Aphis gossypii e pulverizados com azadiractina, extrato aquoso de nim e óleo de mamona ${ }^{(1)}$.

\begin{tabular}{|c|c|c|c|}
\hline Tratamento & $\begin{array}{l}\text { Mortalidade } \\
\text { larval }\end{array}$ & $\begin{array}{l}\text { Viabilidade } \\
\text { pupal }\end{array}$ & $\begin{array}{l}\text { Emergência de } \\
\text { adultos }\end{array}$ \\
\hline & $---\cdot$ & ------ $(\%)--$ & 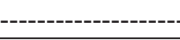 \\
\hline & \multicolumn{3}{|c|}{ 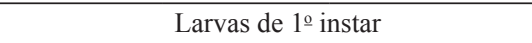 } \\
\hline Azamax $0,25 \%$ & $96,7 \pm 0,33 \mathrm{c}$ & $3,3 \pm 0,33 \mathrm{c}$ & $0,0 \pm 0,0 \mathrm{c}$ \\
\hline Azamax $1,5 \%$ & $100 \pm 0,00 \mathrm{~d}$ & - & - \\
\hline Extrato de nim $1,0 \%$ & $96,7 \pm 0,33 \mathrm{c}$ & $3,3 \pm 0,33 \mathrm{c}$ & $0,0 \pm 0,0 \mathrm{c}$ \\
\hline Extrato de nim $2,25 \%$ & $100 \pm 0,00 \mathrm{~d}$ & - & - \\
\hline Óleo de mamona $1,25 \%$ & $50,0 \pm 1,53 \mathrm{~b}$ & $50,0 \pm 1,53 \mathrm{~b}$ & $46,7 \pm 1,20 \mathrm{~b}$ \\
\hline Óleo de mamona $3,0 \%$ & $100 \pm 0,00 \mathrm{~d}$ & - & - \\
\hline \multirow[t]{2}{*}{ Testemunha (Água) } & $0,0 \pm 0,00 \mathrm{a}$ & $100 \pm 0,00 \mathrm{a}$ & $96,7 \pm 0,33 \mathrm{a}$ \\
\hline & \multicolumn{3}{|c|}{ Larvas de $4^{\circ}$ instar } \\
\hline Azamax $0,25 \%$ & $87,5 \pm 0,43 \mathrm{c}$ & $12,5 \pm 0,74 \mathrm{c}$ & $0,0 \pm 0,0 \mathrm{c}$ \\
\hline Azamax 1,5\% & $100 \pm 0,00 \mathrm{~d}$ & - & - \\
\hline Extrato de nim $1,0 \%$ & $73,3 \pm 0,33 \mathrm{c}$ & $26,7 \pm 0,84 \mathrm{c}$ & $24,9 \pm 0,68 b$ \\
\hline Extrato de nim 2,25\% & $100 \pm 0,00 \mathrm{~d}$ & - & - \\
\hline Óleo de mamona $1,25 \%$ & $43,3 \pm 1,20 \mathrm{~b}$ & $56,7 \pm 1,36 \mathrm{~b}$ & $49,8 \pm 0,64 b$ \\
\hline Óleo de mamona $3,0 \%$ & $96,7 \pm 0,33 \mathrm{c}$ & $3,3 \pm 0,33 \mathrm{~d}$ & $0,0 \pm 0,0 \mathrm{c}$ \\
\hline Testemunha (Água) & $0,0 \pm 0,00 \mathrm{a}$ & $96,7 \pm 0,33 \mathrm{a}$ & $96,7 \pm 0,33 \mathrm{a}$ \\
\hline
\end{tabular}

${ }^{(1)}$ Média \pm EP seguida de letras iguais, para cada um dos instares, não diferem entre si, pelo teste de Tukey, a $5 \%$ de probabilidade. foram desconsiderados para o cálculo de percentagem de emergência.

O extrato aquoso de nim à concentração de 1,0\%, apesar de ter causado $100 \%$ de mortalidade para larvas de $1^{\circ}$ instar, causou mortalidade de $73,3 \%$ para larvas do $4^{\circ}$ instar, além de $24,9 \%$ de emergência de adultos, o que mostra uma menor suscetibilidade deste instar larval. No entanto, é importante ressaltar que, em todos os tratamentos com produtos à base de nim, a duração do $4^{\circ}$ instar atingiu, em média, 16 dias, enquanto que, na testemunha, a duração foi cerca de 4,8 dias.

Tanto a ocorrência de adultos malformados quanto o prolongamento do último instar larval podem estar associados ao modo de ação do nim, que funciona como regulador de crescimento, com interferência no balanço hormonal do ecdisônio e do hormônio juvenil e atuação direta nos processos de síntese de quitina, muda e pupação (Mordue \& Backwell, 1993; Martinez, 2002).

Resultados de prolongamentos do último instar larval, alterações morfológicas e mortalidade de larvas de $1^{\circ}$ e $4^{\circ}$ instares de $C$. sanguinea também foram relatados por Cosme et al. (2007), que utilizaram tratamentos com Nim-I-Go a 50 e $100 \mathrm{mg} \mathrm{L}^{-1}$. Souza (2010) observou mortalidade de $100 \%$ de larvas de $2^{\circ}$ instar dessa joaninha, quando submetidas a $0,0148 \mu \mathrm{g} \mathrm{mL}^{-1}$ de i.a. de óleo de nim na formulação comercial DalNeem. Venzon et al. (2007) observaram efeitos letais e subletais sobre a joaninha $E$. connexa, nas concentrações 0,25 e $0,5 \%$ de extrato de nim.

O óleo de mamona, apesar de causar mortalidade de 100 e $96,7 \%$ para $C$. sanguinea nos $1^{\circ}$ e $4^{\circ}$ instares larvais, à concentração de 3,0\%, mostrou ação letal reduzida sobre ambos os instares à concentração de $1,25 \%$, com emergência de adultos de 46,7 e $48,9 \%$ para os $1^{\circ}$ e $4^{\circ}$ instares, respectivamente. Porém, nesta concentração, o óleo de mamona possui baixo efeito letal e subletal para A. gossypii.

É importante salientar que no manejo integrado de pragas os inseticidas devem ser eficientes no controle da população da praga-alvo, bem como seletivos aos organismos benéficos. Neste sentido, os inseticidas botânicos testados no presente trabalho devem ser utilizados de forma cautelosa, quando constatada a presença de C. sanguinea no agroecossistema, por não mostrarem, em concentrações eficientes para o manejo de $A$. gossypii, seletividade fisiológica à joaninha predadora. 


\section{Conclusões}

1. Os inseticidas botânicos azadiractina, extrato aquoso de nim e óleo emulsionável de mamona possuem efeitos inseticidas letais e subletais a Aphis gossypii, e são promissores para seu manejo.

2. A azadiractina é o inseticida de maior efeito letal e subletal sobre $A$. gossypii, pois causa maior mortalidade e taxas instantâneas de crescimento $\left(\mathrm{r}_{\mathrm{i}}\right)$ negativas a concentrações menores.

3. Os inseticidas botânicos testados afetam negativamente o desenvolvimento de larvas de $1^{\circ}$ e $4^{\circ}$ instares do predador Cycloneda sanguinea.

\section{Agradecimentos}

À Fundação de Amparo à Ciência e Tecnologia do Estado de Pernambuco e ao Conselho Nacional de Desenvolvimento Científico e Tecnológico, por concessão de bolsas.

\section{Referências}

ALMEIDA, Í.P. de; DUARTE, M.E.M.; MATA, M.E.R.M.C.; FREIRE, R.M.M.; GUEDES, M.A. Armazenamento de feijão Macassar tratado com mamona: estudo da prevenção do Callosobruchus maculatus e das alterações nutricionais do grão. Revista Brasileira de Produtos Agroindustriais, v.7, p.133-140, 2005.

ANDRADE, L.H. de. Efeitos de formulações de inseticidas botânicos e óleos essenciais sobre a biologia e comportamento de Aphis gossypii Glover (Hemiptera: Aphididae), em algodoeiro. 2010. 72p. Tese (Doutorado) - Universidade Federal Rural de Pernambuco, Recife.

BOIÇA JÚNIOR, A.L.; SANTOS, T.M.; KURAMISHI, A.K. Desenvolvimento larval e capacidade predatória de Cycloneda sanguinea (L.) e Hippodamia convergens Guérin-Men. alimentadas com Aphis gossypii Glover sobre cultivares de algodoeiro. Acta Scientiarum. Agronomy, v.26, p.239-244, 2004.

BREDA, M.O.; OLIVEIRA, J.V. de; ANDRADE, L.H. de. Eficácia de inseticidas botânicos no controle do pulgão do algodoeiro, Aphis gossypii Glover (Hem.: Aphididae), em condições de laboratório. Boletín de Sanidad Vegetal Plagas, v.36, p.165-170, 2010.

CARVALHO, L.P. de. Cultivo do algodão herbáceo na agricultura familiar: cultivares. Campina Grande: Embrapa Algodão, 2006. (Embrapa Algodão. Sistemas de produção, 1). Disponível em: < http://sistemasdeproducao.cnptia.embrapa.br/FontesHTML/ Algodao/AlgodaoAgriculturaFamiliar_2ed/cultivares.html>. Acesso em: 26 nov. 2010.

COSME, L.V.; CARVALHO, G.A.; MOURA, A.P. Efeitos de inseticidas botânicos e sintéticos sobre ovos e larvas de Cycloneda sanguinea (Linnaeus) (Coleoptera: Coccinellidae) em condições de laboratório. Arquivo do Instituto Biológico, v.74, p.251-258, 2007.
DESNEUX, N.; DECOURTYE, A.; DELPUCH, J.M. The sublethal effects of pesticides on beneficial arthropods. Annual Review of Entomology, v.52, p.81-106, 2007.

FURTADO, R.F.; SILVA, F.P. da; LAVÔR, M.T.F. de C.; BLEICHER, E. Susceptibilidade de cultivares de Gossypium hirsutum L. r. latifolium Hutch a Aphis gossypii Glover. Revista Ciência Agronômica, v.40, p.461-464, 2009.

GABRIEL, D. Pulgão do algodoeiro: um sério problema. 2010. Disponível em: <http://www.infobibos.com/Artigos/2010_1/ pulgao/index.htm>. Acesso em: 26 nov. 2010.

GUERREIRO, J.C.; SILVA, R.A.; BUSOLI, A.C.; BERTI FILHO, E. Coccinelídeos predadores que ocorrem no estágio inicial da cultura do algodoeiro em Jaboticabal, SP, Brasil. Revista de Agricultura, v.77, p.161-168, 2002.

MARTINEZ, S.S. (Ed.). O nim - Azadirachta indica: natureza, usos múltiplos, produção. Londrina: IAPAR, 2002. 142p.

MORDUE, A.J.; BLACKWELL, A. Azadirachtin: an update. Journal of Insect Physiology, v.39, p.903-924, 1993.

MORDUE, A.J.; MORGAN, E.D.; NISBET, A.J. Azadirachtin, a natural product in insect control. In: LAWRENCE, I.G.; SARJEET, S.G. (Ed.). Insect control: biological and synthetic agents, 2010. p.185-197.

OLIVEIRA, J.E.M.; BORTOLI, S.A.; SANTOS, R.F.; MOREIRA, A.N. Desenvolvimento de metodologia de criação e multiplicação de Aphis gossypii: avanços e sucessos. Comunicata Scientiae, v.1, p.65-68, 2010.

QUEIROGA, V. de P.; CARVALHO, L.P. de; CARDOSO, G.D. Cultivo do algodão colorido orgânico na região semi-árida do Nordeste Brasileiro. Campina Grande: Embrapa Algodão, 2008. 49p. (Embrapa Algodão. Documentos, 204).

RIBEIRO, L. do P.; DEQUECH, S.T.B.; RIGO, D.S.; FERREIRA, F.; SAUSEN, C.D.; STURZA, V.S.; CÂMERA, C. Toxicidade de inseticidas botânicos sobre Eriopis connexa (Coleoptera: Coccinellidae). Revista da FZVA, v.16, p.246-254, 2009.

SANTA-CECÍLIA, L.V.C.; GONÇALVES-GERVÁSIO, R. de C.R.; TÔRRES, R.M.S.; NASCIMENTO, F.R. do. Aspectos biológicos e consumo alimentar de larvas de Cycloneda sanguinea (Linnaeus, 1763) (Coleoptera: Coccinelidae) alimentadas com Schizaphis graminum (Rondani, 1852) (Hemiptera: Aphididae). Ciência e Agrotecnologia, v.25, p.1273-1278, 2001.

SANTIAGO, G.P.; PÁDUA, L.E. de M.; SILVA, P.R.R.; CARVALHO, E.M.S.; MAIA, C.B. Efeitos de extratos de plantas na biologia de Spodoptera frugiperda (J. E. Smith, 1797) (Lepidoptera: Noctuidae) mantida em dieta artificial. Ciência e Agrotecnologia, v.32, p.792-796, 2008.

SANTOS, T.M. dos; COSTA, N.P.; TORRES, A.L.; BOIÇA JÚNIOR, A.L. Effect of neem extract on the cotton aphid. Pesquisa Agropecuária Brasileira, v.39, p.1071-1076, 2004.

SANTOS, W.J. Pragas do algodoeiro. In: SANTOS, W.J. (Ed.). Mato Grosso: liderança e competitividade. Rondonópolis: Fundação MT; Campina Grande: Embrapa-CNPA, 1999. p.113-149.

SAS INSTITUTE. SAS/STAT user's guide. Version 8.02. Cary: SAS Institute, 2001. 
SYSTAT SOFTWARE. SigmaPlot for windows. Version 10.0. San Jose: Systat Software, 2006.

SOARES, J.J.; BUSOLI, A.C. Efeito de inseticidas em insetos predadores em culturas de algodão. Pesquisa Agropecuária Brasileira, v.35, p.1889-1894, 2000.

SOUZA, C.R. de. Impacto de inseticidas sobre artrópodes do dossel e da superfície do solo na cultura da melancia. 2010. 66p. Dissertação (Mestrado) - Universidade Federal do tocantins, Gurupi.

SOUZA, M.C.M. de. Produção de algodão orgânico colorido: possibilidades e limitações. Informações Econômicas, v.30, p.91-98, 2000.
STARK, J.D.; BANKS, J.E. Population-level effects of pesticides and other toxicants on arthropods. Annual Review of Entomology, v.48, p.505-519, 2003.

VENZON, M.; ROSADO, M. da C.; PALLINI, A.; FIALHO, A.; PEREIRA, C. de J. Toxicidade letal e subletal do nim sobre o pulgão-verde e seu predador Eriopis connexa. Pesquisa Agropecuária Brasileira, v.42, p.627-631, 2007.

WANDERLEY JUNIOR, J.S.A.; MELCHIOR, S.N.B.; SANTOS, F.N.; SANTOS I.C.S. Sistema de produção de algodão agroecológico no Agreste paraibano. Revista Brasileira de Agroecologia, v.4, p.3010-3013, 2009.

Recebido em 4 de março de 2011 e aprovado em 17 de outubro de 2011 